\title{
Creating Feminist Spaces: Occupying Hostile Environments
}

\author{
Kate Smith ${ }^{\mathrm{a}}$, Grainne McMahon ${ }^{\mathrm{b}}$ and Anna Davidson ${ }^{\mathrm{c}}$ (these names appear in \\ no particular order)
}

${ }^{a b}$ Human and Health Sciences, University of Huddersfield, Huddersfield, United Kingdom

${ }^{c}$ Applied Sciences, University of Huddersfield, Huddersfield, United Kingdom

* Kate Smith is a Research Fellow (Asylum and Migration) in the School of Human and Health

Sciences at the University of Huddersfield. Working also as a Practitioner Manager at WomenCentre her research is in the field of migration and refugee studies, with a particular focus on the narratives of women, and on topics relating to vulnerability and resistance. ORCiD: https://orcid.org/0000-0002$\underline{3240-8233}$

Anna Davidson is a Lecturer in Human Geography. Her latest research is on the feminist politics of urban cycling and she works with community groups on climate action and unlearning racism. Twitter:@acdavids ORCiD: https://orcid.org/0000-0002-4330-3680

Grainne McMahon is a Senior Lecturer in Sociology in the School of Human and Health Sciences at the University of Huddersfield, and Research Lead for the human rights organisation, RAPAR. She researches feminist and human rights activism and social movements, and young people's participation, and utilises co-equal and co-created methodologies in her work. Twitter: (a)grainnemcmahon.

\footnotetext{
${ }^{1}$ Dr Kate Smith - Email Kate.Smith@hud.ac.uk
} 


\section{Creating Feminist Spaces: Occupying Hostile Environments}

We are a new, small and emerging social justice network of feminist activists, academics and community workers, building a collaborative, capacity-releasing feminist network by making connections between UK and globally-based allied projects of resistance. We work to create co-equal and co-creative safe(r) spaces and share our lived experiences of occupying and resisting hostile environments where we have been made to be out of place, unwelcome and unsafe. We do not assume that these spaces are felt in common between us, but they enable us to take up our own space, to tell our own stories, to move across boundaries and borders, to be heard and visible (where desired), and to resist. Using arts-based methods of enquiry, we pose living questions in our work together which are ongoing and ever-adapting alongside our lived experiences of occupying and resisting hostile environments.

Keywords: feminism; space; hostile environment; resistance; co-creative 


\title{
Creating Feminist Spaces: Occupying Hostile Environments
}

\author{
The Common Language of She
}

0.

She spins the globe between her thumb and fingers

Sits back, smiles and says, "we're all in it."

We pass the world between us.

(Opening lines of a poem by Lisa Luxx (lisaluxx.com) created in a Feminist Spaces workshop. The quotes below are excerpts from the poem.)

The project - Creating Feminist Spaces: Occupying Hostile Environments (feministspaces.net) - was set up in January 2019 through a university seedcorn grant. Feminist Spaces is an emerging social justice network of feminist activists, academics and community workers, seeking to subvert and work against the dominant (neo-) colonial practices of international research and aid and to build a collaborative, capacity-releasing feminist network. One of the ways we do this is by making connections between UK and globally-based allied projects in less economically developed countries ${ }^{2}$.

As Feminist Spaces, we take up space, resist and occupy the hostile environments ${ }^{3}$ that seek to oppress and bound us. We work to create co-equal and co-creative spaces to share our diverse experiences and understandings of resistance, womanhood ${ }^{4}$, and feminism, in hostile

\footnotetext{
${ }^{2}$ Countries in receipt of Official Development Assistance.

${ }^{3}$ We use the term 'hostile environments' in recognition of the political context of the United Kingdom and its specific policies on migration geared towards making the UK a 'hostile environment'. All of us participating in the Feminist Spaces workshops are currently resident in the United Kingdom.

${ }^{4}$ Broadly, we use the term 'women' to refer to people who identify as women, trans or gender nonbinary. Our use of the terms 'womanhood' 'feminism' and their meanings, (in)coherence, ex/inclusions and implications, has been a recurrent topic of discussion amongst the current authors.
} 
environments where we are made to be out of place, where our presence is often unwelcome, and where power is increasingly enacted through the demarcation and policing of spaces. These spaces are not felt or experienced in common between us, but are imbued with multivalent her/histories and meanings.

When our bodies and stories are not socially, politically and legally entitled to take up (as much) space as others, staying and existing in spaces, moving across boundaries and borders, being heard and visible, or remaining undetected, are acts of resistance.

Hang back, I linger, lurking in between pillars, I turn myself into a shadow to hide. My whole ancestral line taught me this is how to survive.

Feminist Spaces is a growing network of partners, including The Racial Justice Network (Leeds), Women in Exile and Women Together (Kirklees), RAPAR (Manchester), the Women's Media and Culture Organization (Sulaymaniyeh, Iraq), Hidden Voices (Kenya), and an emerging activist network in Botswana. In 2019, our UK-based partners came together in two workshops to share our lived experiences of occupying and resisting hostile environments.

In the first workshop, we utilised co-creative methods to make connections between us.

\footnotetext{
In most of what we have written, we have asterisked or added a footnote to the term woman* to state that 'we use the term 'woman' to refer to all those who identify as women, trans or gender nonbinary'. In doing so, we are acutely aware that the dominant binarisation of gender is not going to be toppled by a footnote seeking to include 'others' into the normative, binarised term we continue to use. Questioning the universalism and essentialism of 'womanhood' (Grosz, 1995) has been a focal point of - in particular - material, queer and black feminisms, which question the white feminist tendency 'to situate (white) gender difference as the foundational position from which they speak' (Mirza \& Gunaratnam, 2014, p. 129). However, in our workshops and website we have left 'woman' and 'feminisms' as largely undefined. We are aware that this suspension of definition might create both a space for diverse and competing definitions, as well as harm. For now, we have emphasised the hostility of our environments and the varying strategies we employ to survive them, rather than necessarily how we define ourselves, individually or collectively.
} 
Release is putting down what we have held this far,

So we can take happiness onwards;

Happiness is two empty palms

Offering themselves as unwrapped presents.

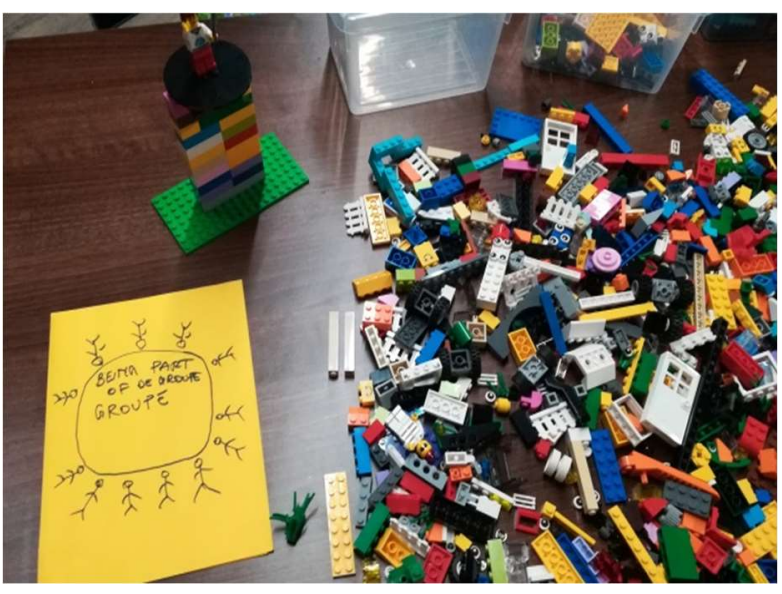

Our scattered Lego bundle (C) Feminist Spaces

We used Lego and drawing to explore concepts of 'safe(r)' spaces (The Roestone Collective, 2014) and outlined our planned projects of resistance: Hidden Voices delivered mental health sessions in two schools in Kenya looking at sexual assault and domestic abuse; Kani Kamil (kanikamil.com) worked with Women in Exile to facilitate four workshops supporting women refugees to talk about what inhibits/supports them in their freedoms, forming an artwork created by sewing the statements, using thread or women's own hair, in mini looms in different languages; Zenebu Hailu worked with Women Together producing an art-exhibition, 'Mirrors of Us', bringing together stories of displaced experiences; and RAPAR conducted a photoethnography of Manchester's urban environment with two women assigned refugee status beginning their feminist journeys. 
The first workshop included Candice Purwin, who illustrated some of the central themes of the workshop. In the second workshop, the poet Lisa Luxx crafted our words into the poem, The Common Language of She.

This poem has no author.

It is written by vertebrae cracking into place. Eight backs of bone and flesh, women of nerve and duress.

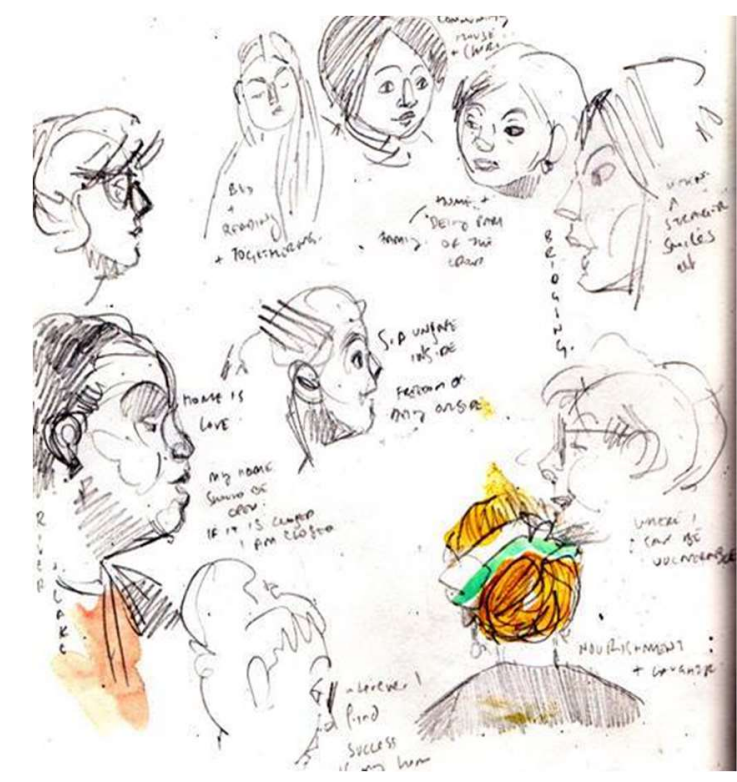

Illustrations by candicepurwin.com, (C) Feminist Spaces

Feminist Spaces focuses on 'living' questions, open to multiple interpretations and directions, drawing upon some of our learning from the workshops, our poem, and our artworks.

Our first question asks about the embodied strategies that intersectional feminists use to resist oppression, in contexts where being 'othered' (e.g. through gender, race, nationality or settlement status, religion, sexuality, income or class), and made to be 'out of place', is an increasingly dominant political strategy.

Ink hemmed us into the history of ourselves

We take needle as pen now, hair as thread;

Spelling words we never dared say.

Kani's work with women refugees forms several incantations of feminist space: the collaborative space of weaving together shared, often unheard her/hair-stories in multiple 
languages; the artworks place women's hair expressly 'out of place' and their framing and display in public spaces speak taboos.

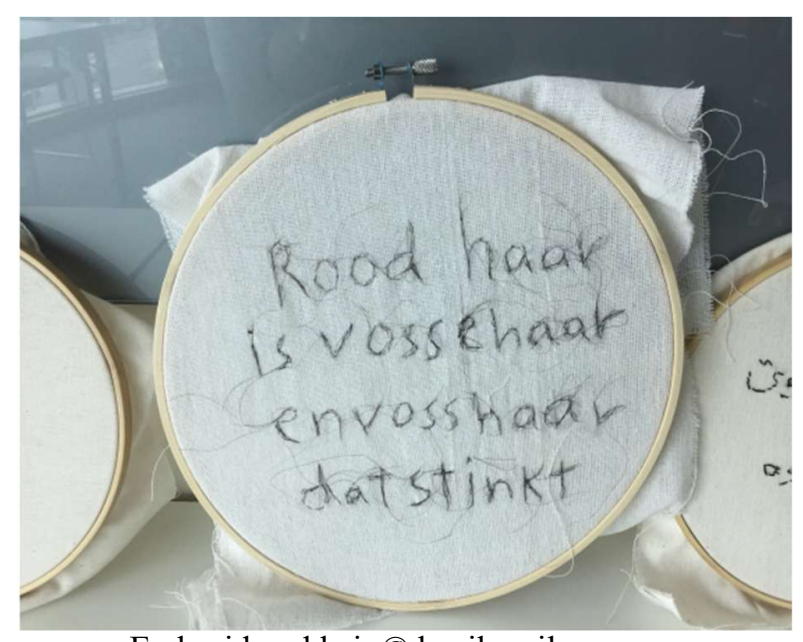

Embroidered hair (C) kanikamil.com

We reflect together on how we use our hair to subvert dominant messages, pressures and violence. We name hair as one symbol of femininity that makes us feel conflicted and confident, and how we have made our hair political; we laugh at the inability of some to 'read' or 'understand' our hair, its presence/lack or removal, and we think about how our bodies - often scarred and damaged, healthy and resourced - become sites of protest and resistance.

Raise my eyebrows / Cut off my hair / Apply lipstick / Scowl / Choose flat shoes / Walk towards you with my shoulders and hips swaying proud.

Our second question asks how activist/academic groups, at very different intersections of 'otherness' and in different geographical contexts, can connect and learn from one another. We talk about what we want this space to become and keeping Feminist Spaces safe (enough) while also recognising the contestations around safety (The Roestone Collective, 2014).

We speak many languages - Arabic, English, Irish, Persian, Lingala, Portuguese, Uzbek, Dutch, Amharic, German, Czech - using different words to describe the social, political and her/historical contexts and forces that shape and inform our diverse sense of privileges and feminist identities.

Learn that feminist in Lingala is bo muasi

We hear each other's stories in order to connect and learn from each other: 
And that you can't connect with someone else without changing yourself.

Compassion is painted art on mirrors, so you see you

While looking at another person's heart.

We think of ourselves as a fledgling, fragile/strong movement of feminists who share and contest 'sameness' and 'difference'. In all of our work, it is important to try to avoid the violence that can be done by presuming that 'we are all the same'. Yet we have found a need for a form of 'common language of she', even if the notion of 'she' is interpreted, spoken, lived and enacted in different ways. So, we share stories of our lives and how we relate to safety, to spaces where we do and do not (want to) fit in, and what it might

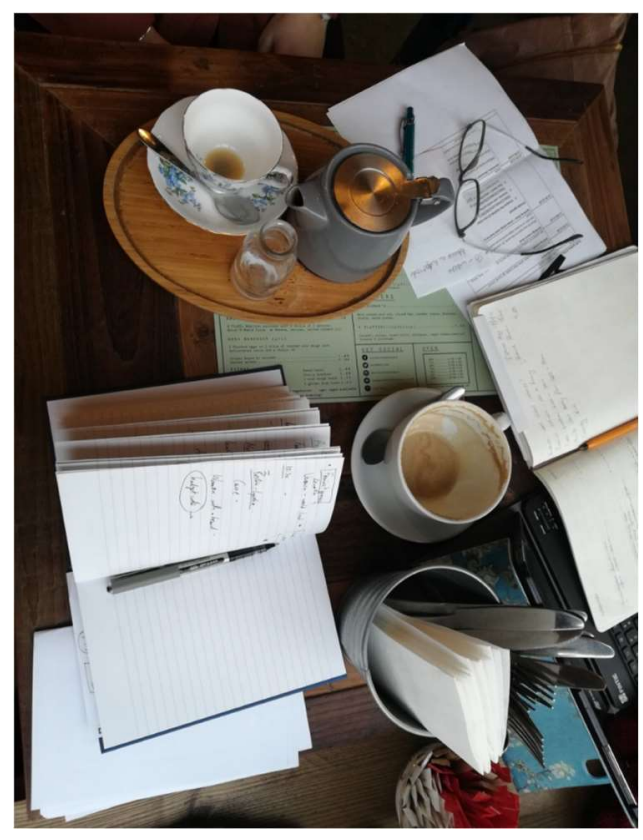

Tea and Feminist Spaces (C) Feminist Spaces take to make us safe and welcome.

As a woman seeking asylum I go to Primark to feel safe, price tags like invites. The sale never has clothes that fit. I'm too big. They wish I would fold myself into tiny things. I turn them over in my hands, wrists smelling like perfume testers that I spritz because

As a woman

As a woman

As a woman

I deserve it. I deserve a wardrobe and unfolded clothes, I deserve to unpack my suitcase and have money of my own.

This social justice network contributes to understandings of co-creating embodied and online safe(r) feminist spaces. So far, we have considered safe(r) places, literally, and the ways that we subvert, challenge and resist dominant messages about where we are and are not welcome 
by creating our own safe (enough) spaces. Our stories return time and again to our bodies in our spaces.

Let grey grow without dye / Lower the lids over my eyes / Run along main roads with friends / Raise my head on the same bus I once cowered in.

I am noise

Before I even open my mouth / Crossing borders

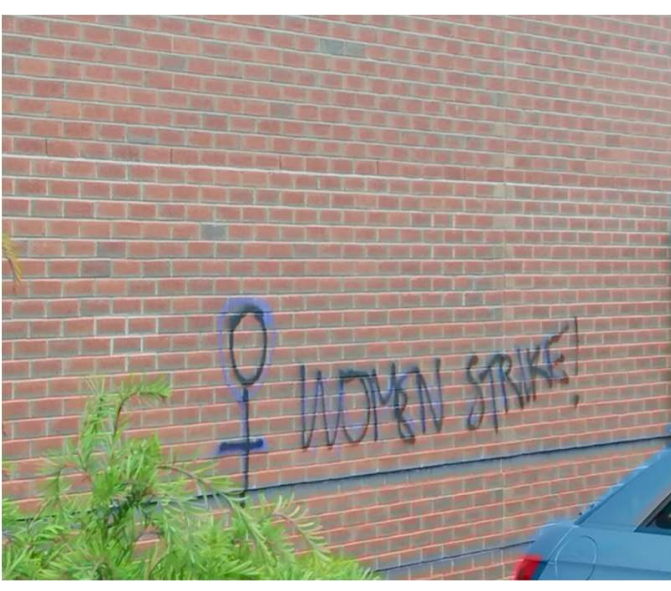

Image from RAPAR's photoethnography (C) Feminist Spaces
Our experiences of sharing ideas and stories from our lives in short films, artwork and workshops raises many questions for us about the ethics and politics of using feminist, collaborative, arts-based and mixed-media methods of inquiry to explore our lived experiences of occupying and resisting hostile environments. These are some of the questions our work has raised, and continues to explore,

which could inform other activists and/or scholars:

- How do we ensure co-creation rather than individualised production of mixed-media content and of our shared (physical and virtual) spaces?

- How do we find a balance between in-person creation of space and sharing of stories and a digital presence (website) for wider dissemination?

- How do we nurture an openness to difference and definitions of womanhood and feminism (see footnote) and have challenging conversations that emphasise doing, making, acting and embodiment, rather than 'purity of political expression' (Dejmanee, 2016) or definition? 
- How do we ensure a sensitivity to the potential harms in telling stories (Page, 2017) through mixed-media (re-traumatisation or exposure in re-telling stories of trauma) and put in place strategies for minimising harm (e.g. 'trigger' warnings, flexible timings, ability to come and go)?

- How do we establish the ethics of where our stories and outputs go, our intended audience, and our safety in public dissemination (Clark-Parsons, 2018)?

- And finally, how can we - collectively or individually - effect changes to hostile environments using feminist, collaborative, arts-based and mixed-media methods of learning?

Using arts-based methods of enquiry, we extend existing ways of documenting our work disrupting and exposing the tenuousness of the boundary between occupying feminist spaces both on and offline (McGerty, 2000; Bowles Eagle, 2015). Exploring and making visible how embodied strategies can be used to resist oppression, our project deepens understandings of the multiple ways in which people, at very different intersections of 'otherness' and in different geographical contexts, can connect and learn from one another to build a collaborative, capacity-releasing feminist network.

Looking forward to the future we are co-creating, we share our herstories, speak our resistances and ask questions of each other, nudging towards understanding.

She holds the globe to her chest.

A hiss escapes as she deflates it

And we discuss what's coming next. 


\section{References}

Baer, H. (2015). Redoing feminism: digital activism, body politics, and neoliberalism.

Feminist Media Studies, 16(1), 17-34. doi:10.1080/14680777.2015.1093070

Bowles Eagle, R. (2015). Loitering, Lingering, Hashtagging: Women Reclaiming Public Space Via \#BoardtheBus, \#StopStreetHarassment, and the \#EverydaySexism Project. Feminist Media Studies, 15(2), 350-353. doi:10.1080/14680777.2015.1008748

Clark-Parsons, R (2018). Building a digital Girl Army: The cultivation of feminist safe spaces online, New media \& society, 20(6): 2125 -2144.

Dejmanee, T. (2016). Waves and popular feminist entanglements: diffraction as a feminist media methodology. Feminist Media Studies, 16(4), 741-745.

doi:10.1080/14680777.2016.1190046

Grosz, E. (1995). Space, time, and perversion (1st ed.) Routledge. doi:10.4324/9781315656564

McGerty, Lisa-Jane. (2000). Nobody lives Only in Cyberspace: Gendered Subjectivities and Domestic use of the Internet, CyberPsychology and Behavior, 3(5), 895-899.

Mirza, H., \& Gunaratnam, Y. (2014). 'the branch on which I sit': Reflections on black British feminism. Feminist Review, (108), 125-133. Retrieved May 12, 2020, from www.jstor.org/stable/24571928

Page, T. (2017). Vulnerable writing as a feminist methodological practice. Feminist Review, 115(1), 13-29.

The Roestone Collective (2014). Safe space: towards a reconceptualization. Antipode, 46(5), $1346-1365$. 